\title{
Electromagnetic Radiation Causes Weight Loss and Weight Destabilization of Objects with Presumed Elevated Levels of KELEA (Kinetic Energy Limiting Electrostatic Attraction), Relevance to Human Health and to Global Warming
}

\author{
W. John Martin \\ Institute of Progressive Medicine, South Pasadena CA, USA \\ Email: wjohnmartin@ccid.org
}

How to cite this paper: Martin, W.J. (2019) Electromagnetic Radiation Causes Weight Loss and Weight Destabilization of Objects with Presumed Elevated Levels of KELEA (Kinetic Energy Limiting Electrostatic Attraction), Relevance to Human Health and to Global Warming. Journal of Modern Physics, 10, 195-213.

https://doi.org/10.4236/jmp.2019.103015

Received: February 1, 2019

Accepted: February 25, 2019

Published: February 28, 2019

Copyright $\odot 2019$ by author(s) and Scientific Research Publishing Inc. This work is licensed under the Creative Commons Attribution-NonCommercial International License (CC BY-NC 4.0). http://creativecommons.org/licenses/by-nc/4.0/

\section{c) (i) () Open Access}

\section{Abstract}

A natural force has been proposed, which is required to prevent the fusion and disappearance of the discrete electrical charges that are present on electrostatically attached opposing electrical charges. This force may also explain the repulsion between objects with either matching positive or negative electrical charges. The energy of this force is referred to as KELEA (kinetic energy limiting electrostatic attraction). KELEA is especially attracted to dipolar compounds and to other materials with spatially separated opposite electrical charges. These compounds can be used to increase the level of KELEA in water. KELEA activated water can become an added source of KELEA for objects that are placed in close proximity to the water. It is generally held that the weight of an object is solely determined by its mass in relation to that of the earth. Yet, it was previously reported that the measured weight of certain KELEA attracting objects can undergo considerable variability over time. This observation is consistent with the concept that KELEA can contribute to the measured weight of certain objects. The present study strengthens this concept by demonstrating that the weight of cellulose containing materials, including paper, cotton fabrics, and wood, is increased if the materials are placed close to containers of KELEA activated water. It is further shown that electromagnetic radiation can significantly reduce the added weight of the KELEA exposed cellulose containing materials. Moreover, the previously added weight of the materials can be regained by replacing the materials back 
into the KELEA enhanced environment. It is proposed that the electrical charges that accompany electromagnetic radiation are able to competitively withdraw some of the KELEA from certain KELEA-enhanced objects. This effect can be reliably demonstrated using single sheets of writing paper, which are primarily composed of mechanically-bonded, branched cellulose fibers. There can be considerable fluctuations of the weight of the materials exposed to electromagnetic radiation after having been placed nearby to KELEA activated water. The weight instability is interpreted as being due to the electromagnetic radiation also triggering a dynamic process of rapid additions and removals of significant quantities of KELEA to and from objects. These observations are relevant to the further understanding of KELEA and to the potential health and climate consequences of manmade electromagnetic radiation causing a reduction in the environmental levels of KELEA.

\section{Keywords}

KELEA, Alternative Cellular Energy, Paper, Cotton, Wood, Cellulose, Activated Water, Weight, Gravity, Weather, Global Warming, Clouds, Electrostatic, Electromagnetic Radiation, Radio Waves, Microwaves, Cosmic Waves, Inkjet Printing, Electropollution

\section{Introduction}

As previously reported, there can be fluctuations in the measured weights of certain objects when the objects are repeatedly weighed over a period of several days [1]. It was proposed that the increases in weight were due to the involvement of a natural force termed KELEA (kinetic energy limiting electrostatic attraction). The primary function of KELEA is presumably to prevent electrostatically attracted opposite electrical charges from being eliminated by fusion with one another [2] [3].

Dipolar compounds with separated electrical charges are able to attract KELEA from the environment [4]. Certain of these compounds can transfer some of the attracted KELEA to nearby fluids, including water; possibly in an oscillatory manner. When absorbed into fluids, KELEA can lead to a loosening of the intermolecular hydrogen bonding, with a lowering of surface tension and an increase in volatility [5]. The increased volatility of KELEA activated water can be measured as a faster loss of weight of the activated water when compared with control water, when the water samples are placed into caped, but not completely sealed, containers [4].

Similar to KELEA attracting and releasing dipolar compounds, KELEA activated water can lead to the increased volatility of added regular water [6]. It can also activate regular water, which is positioned nearby to KELEA activated water [7] [8]. Presumably, the loosened hydrogen bonding in the KELEA activated water adds to the level of electrical charges on the water molecules. This would result in a greater attraction of KELEA from the environment. Again, possibly in 
an oscillatory manner, much of the additionally attracted KELEA could be radiated from the activated water. KELEA activated water can, thereby, establish a heightened KELEA enriched environment.

Approximately two gallons of KELEA activated water in numerous $2 \mathrm{oz}$ bottles and in several larger containers are routinely stored in the same room as an electronic balance. Various items were selected to be placed near the containers of KELEA activated water to see if their weight would show a discernable increase. Individual sheets of typing paper were among the items tested. The initial reasoning for using typing paper was to see if inkjet-printing of multiple lines of text onto the paper would create linear arrays of negatively charged ink against a background of essentially neutral or induced slightly positively charged blank regions of the paper [9]. The multiple charges on the printed sheets of paper could potentially attract KELEA onto the paper and this would be seen as an increase in the weight of paper from being placed in the KELEA-enriched environment. This predicted increase in the weight of printed sheets of paper was confirmed, but this was also shown, to a somewhat lesser extent, for blank sheets of paper on which there was no printed text. More surprising was the relatively rapid decreasing of the weight of the KELEA exposed paper during the time it was being weighed in an electronic balance. Similar measurable weight gains from a KELEA enriched environment and the subsequent weight losses when placed onto the balance were made with both printed and non-printed cotton fabrics and with unprocessed wood. The tentative interpretation of the findings is that KELEA activated water can transfer KELEA to cellulose containing and certain other materials and that electromagnetic radiation emitted by the electronic balance is able to remove the added KELEA from these materials. This article outlines the experiments leading to this interpretation. The article also discusses some of the likely health and climate related implications of the findings.

\section{Materials and Methods}

KELEA-enriched environment. Water is routinely being activated by the addition of small amounts of various dipolar compounds, followed by several 10 -fold dilutions and filtration through a zero-residue filter. Occasionally other procedures are used such as electrolysis of copper and silver in a potassium citrate solution. About two gallons of KELEA activated water are routinely stored in the same room that has the electronic balance. Bringing regular distilled water into the room will lead to the water becoming activated, as shown by its increased volatility and the linear dissolving pattern and surface breaking ability of sprinkled particles of neutral red dye [4]. The volatility of water is also assessed by the rate of weight loss in closed but not completely sealed containers [4].

Weighing. A Sartorius electronic balance (Type 1702) is located in the same room as the stored KELEA activated water. The balance is used to obtain weight measurements up to 200 grams with a sensitivity level of 0.1 milligram. The balance was originally purchased from Brinkman Instruments, New York. In some 
studies, a non-electronic beam balance (OHAUS Dial-O-Gram $310 \mathrm{gm}$ weight) was used.

Weight-standards. Salter Brass Weights Set (Imperial) Model 063, Salter Hardwares Ltd., Tonbridge Kent UK, was used to confirm the accuracy and stability of routine weighing measurements using the electronic balance. The weight standards used to confirm the accuracy of the balance were $0.25,0.5,1$ and $2 \mathrm{oz}$.

Paper. Individual sheets of regular 8 " $\times 11$ " white paper (Basis weight of $20 \mathrm{lb}$ ) were used in most experiments. The sheet of paper was either repeatedly folded into approximately 2 " $\times 2$ " size or rolled into a cylinder shape. The folded or rolled paper was held in place using either a staple or more commonly a small strip of adhesive tape. The sheets of paper were either left blank (unprinted) or printed with various texts prior to being tested. An Epson XP-820 Inkjet printer was programmed from a computer running Microsoft Word software. To maximize the amount of printing, 5 point, Times New Roman font style, was employed with printing on both sides of the page with minimal margins. The printed pages were allowed to dry for several hours before being tested.

Cotton fabric. Several yards of different colored cotton material were purchased from a local fabric store. The cotton materials were cut into rectangular shapes, the edges of which could be placed within the margins of an " $8 \times 11$ " sheet of paper. For printing, the edges of the cotton were adhered to the paper using transparent tape. The paper sheet could then be fed into the printer so that the printing occurred onto the cotton material. The cotton material could then be turned over to achieve double-sided printing. Several tee shirts with either an adhesive applied image or direct to garment (DTG) printed image were obtained from a local thrift store. The area with the image was cut from the tee shirt and compared with a similar sized non-printed area from the same tee shirt. The printed and unprinted cotton materials were either folded into square to rectangular shapes or measured after being added to a plastic cup, whose weight could be tarred if necessary or simply subtracted from the total weight.

Wood. Store purchased smokehouse wood chips of several individual varieties of wood including cherry, hickory, pecan, oak, apple, etc., were purchased from a local store. Either individual chips or a grouping of several pieces of wood were tested.

Radio. A Nicetex Electronics Ltd., Model NE-368-R, radio with two 5 1/2 square side speakers was used. The radio is powered by 12 Watts delivered from a 120 -volt, $60 \mathrm{~Hz}$ household electrical supply. It was manufactured at HiTech Industrial Park, Hong Kong.

Electromagnetic Field (EMF) Detector, An EMF Detector App was downloaded onto an Apple iphone-6 from the Apple Store. The seller of the App is Ngoc Que Nguyen. EMF values are measured in microTeslars $(\mu \mathrm{T})$.

Photos and videos were obtained using a hand-held iphone- 6 or either a Sony or a Cannon camera mounted onto a tripod. The images were captured onto a 
128 gigabyte Scandisk. In some experiments, a digital timer was placed near the weight display panel of the balance so that photos and videos could be taken of both the displayed weight of the balance and the elapsed time.

\section{Results}

After some initial minor fluctuations, the digital displays of the weight of most items placed onto the weighing pan of the electronic balance become stable. The reaching of a stable weight generally occurs within 10 seconds. The displayed digital reading is then followed by the letter "g" for grams. Unless there are undue movements within the room, the displayed weight of the item will not generally vary by more than $\pm 0.2 \mathrm{mg}$ over a 30 minutes period. Moreover, the measurements are consistent upon reweighing the same object and are not affected by leaving the object in the weighing room. This is noted because the weighing room is where approximately two gallons of KELEA activated water in multiple $2 \mathrm{oz}$ bottles and in several larger containers are regularly stored. The multiple samples of water had previously been tested for increased volatility based on the measured reductions in weight.

The weighing results obtained using single sheets of regular typing paper were quite different. Rolled or folded paper brought directly into the weighing room and placed onto the balance would regularly show more minor fluctuations than did most other objects. This occurred with paper that had either been printed with text or left blank. The results over the first 40 minutes of such an experiment are shown in Figure 1. The beginning weight of the rolled blank sheet of paper was $4.7752 \mathrm{gm}$. At 40 minutes the weight was $4.7751 \mathrm{gm}$. The maximum and minimum recorded weights over the 40 -minute period were $4.7764 \mathrm{gm}$ and $4.7748 \mathrm{gm}$, respectively. The variability in weight, therefore, amounted to 0.0016 gm $(1.6 \mathrm{mg})$. The sheet of paper was left on the balance for an additional $35 \mathrm{mi}$ nutes for a total time of 75 minutes. There was some continuing minor variability as subsequently recorded in 5-minute intervals, but at 50, 60 minutes and 75

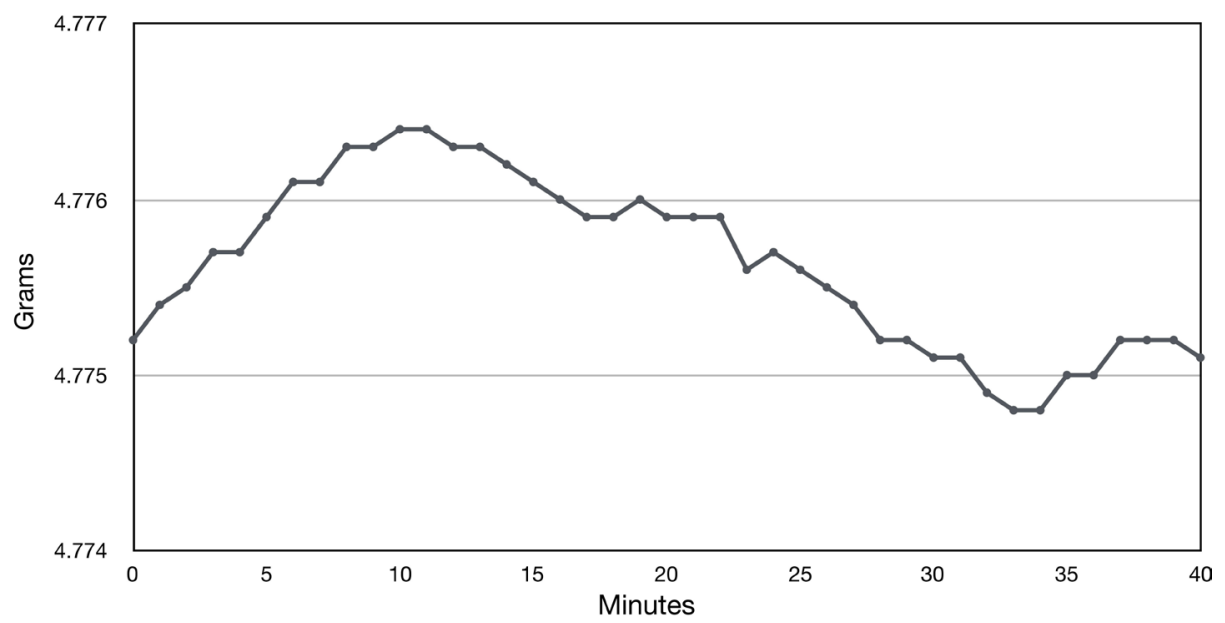

Figure 1. Minor variability over a 40-minute period in the weight of a Non-KELEA exposed sheet of paper. 
minutes, the weight was the same as the initial weight $(4.7752 \mathrm{gm})$. The rolled sheet of paper was removed from the balance at 75 minutes.

It was noted that the reweighing individual rolled or folded sheets of paper after they had been left in the weighing room, would yield values higher than were initially recorded. This observation was consistent with the paper being able to obtain additional KELEA from the KELEA activated water being stored in the room. The increase in weight occurred regardless of whether the paper was printed or blank. For example, the same sheet of paper on which the weight measurements are recorded in Figure 1 was removed from the balance after the 75 -minute period of weighing. It was then placed near to the containers of KELEA activated water for 30 minutes before being reweighed. As noted above, the final reading before removing the paper from the balance was $4.7752 \mathrm{gm}$. During the 30-minute period near the KELEA activated water, the weight of the sheet of rolled paper had increased by $4.7 \mathrm{mg}$ to $4.7799 \mathrm{gm}$.

Leaving this sheet of paper on the electronic balance during the reweighing process led to a progressive reduction of the weight back to the value at which it was initially weighed. The loss of weight over the first 15 minutes of the reweighing process is depicted in Figure 2. During this 15-minute period, the weight of the paper had dropped by $3.8 \mathrm{mg}$ from $4.7799 \mathrm{gm}$ to $4.7761 \mathrm{gm}$. The weight continued to slowly fall during the next 15 minutes at which time the weight was $4.7756 \mathrm{gm}$, nearly the same as when it was initially weighed (4.7752 gm).

Similar findings have been repeatedly obtained with either rolled or folded single sheets of typing paper. Figure 3 shows the marked reduction in weight over a 20-minute period of a rolled printed sheet of paper that was weighed after it had been left overnight in the weighing room. The weight had dropped from $4.6819 \mathrm{gm}$ to $4.6703 \mathrm{gm}$, a difference of $11.6 \mathrm{mg}$. Some of the recorded weights of this sheet of paper at later time points in this experiment are included in the

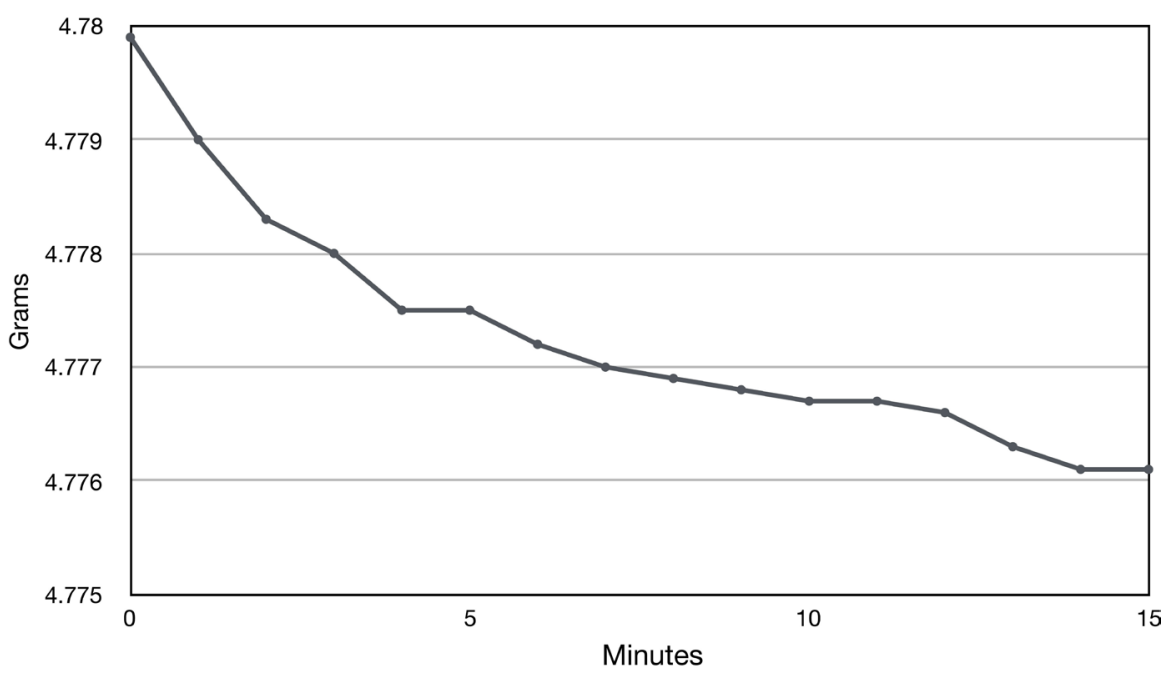

Figure 2. Weight loss during the weighing of paper that had been earlier exposed to containers of KELEA activated water. 


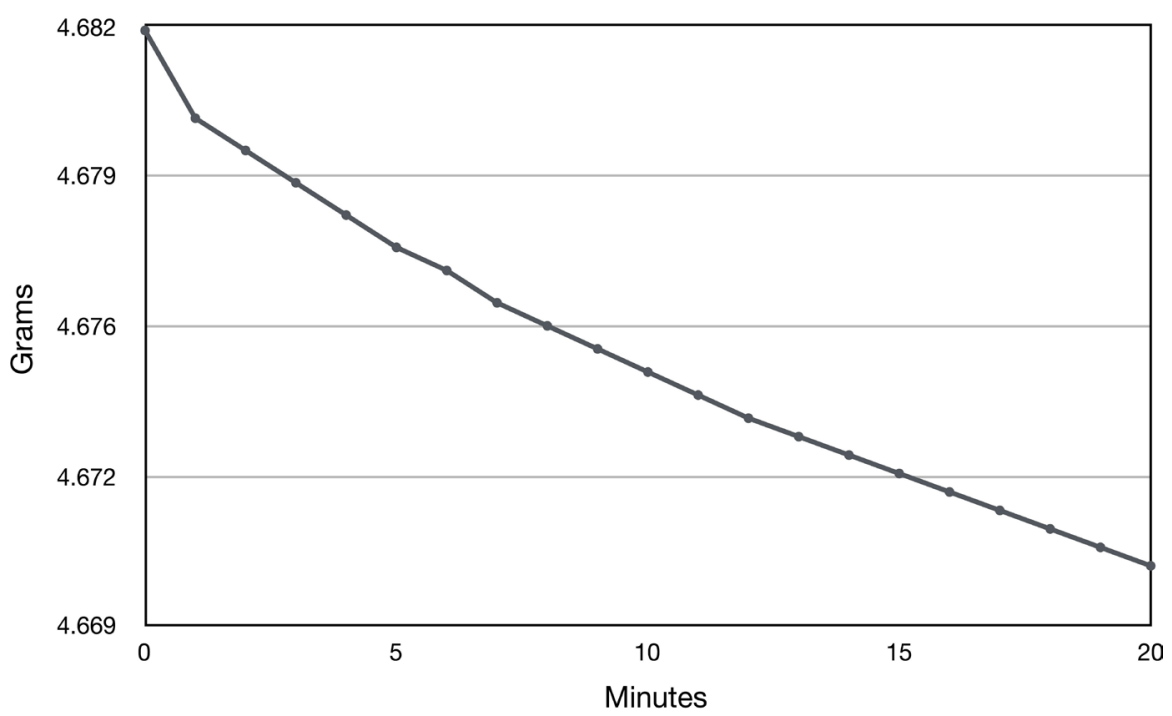

The weight was recorded at various time intervals thereafter. The weights recorded as 40, 50, 60, 90 and 100 minutes on the balance were 4.6634, 4.6611, 4.6591, 4.6586 and 4.6561 grams respectively. Later after the balance had been turned off and the paper sheet left in the weighing room, its weight increased to $4.6685 \mathrm{gm}$.

Figure 3. Weight loss during the weighing of a KELEA exposed sheet of paper.

Legend to Figure 3. Overall, there was a reduction of $25.8 \mathrm{mg}$ from $4.6819 \mathrm{gm}$ to $4.6561 \mathrm{gm}$. The sheet of paper rapidly regained some of the lost weight by being placed near to the containers of KELEA activated water. In other experiments, it was clear that the gain in weight of the paper would not occur if the paper was taken from the balance and placed in a different room. On the other hand, a sheet of paper that had shown an increase in weight from being left near the containers of KELEA activated water would not noticeably lose the added weight when taken to a different room. The gain and loss in weight of a sheet of paper are, therefore, dependent upon the presence of KELEA activated water and the use of the electronic balance, respectively.

An arbitrary criterion was used to establish whether the weight losses during the weighing of a rolled or folded sheet of paper were to be regarded as meaningful. The criterion was that the losses over a 30 -minute period had to be $>1$ mg per gram of the beginning weight of the paper. Over several months of experiments, this criterion was consistently met with paper that had been left in the room with the activated water. There were many examples of weight losses during the first 30 minutes of weighing being $>4 \mathrm{mg} / \mathrm{gram}$. The $1 \mathrm{mg} / \mathrm{gm}$ criterion was not met for the weighing of freshly prepared rolled or folded sheets of paper, which had not previously been in the weighing room or, which had immediately been located outside of the weighing room, after having been weighed for a prolonged period of time. Exceptions included paper that had been placed in an outside garden setting or had been exposed to other presumed KELEA rich environment (unpublished data). Several individual sheets of rolled paper were subjected to repeated experiments. These items showed recurring meaningful gains and losses of weight by being placed near KELEA activated water and then 
being weighed in the electronic balance, respectively. The quantitative results from individual experiments varied, however, even when performed using the same paper item. In spite of indications of an increased sensitivity of printed paper, the use of blank paper has advantages of convenience and better standardization.

A series of experiments were performed using printed and non-printed cotton fabrics, which have been weighed directly upon being brought into the weighing room and/or have been weighed after being stored for some time in the weighing room near the containers of KELEA activated water. Cotton fabric brought directly into the weighing room for immediate weighing would generally show no weight loss if left on the balance for several hours. A slight gain in weight was occasionally noted. Considerable weight gain would progressively occur in pieces of cotton fabric, which were placed nearby to the containers of KELEA activated water. This is illustrated in Figure 4. It shows the increasing weight of a piece of cotton fabric over the first 6 hours after it was brought into the weighing room. During this time, the weight increased from $54.2593 \mathrm{gm}$ to $54.3070 \mathrm{gm}$, an increase of $47.7 \mathrm{mg}$.

As anticipated from the studies with paper, there was a significant reversal of the added weight of cotton fabrics left in the weighing room when the cotton fabrics were subsequently continually weighed in the electronic balance. An example of weight loss upon weighing a piece of cotton fabric that had been left in the weighing room for several days is shown in Figure 5. Over the first 60 minutes its weight dropped by $25.3 \mathrm{mg}$ from $13.5392 \mathrm{gm}$ to $13.5139 \mathrm{gm}$. The weight loss continued over the next several hours with the weight at 2 and 9 hours after the start of the weighing being recorded at $13.5076 \mathrm{gm}$ and $13.4905 \mathrm{gm}$, respectively. There was no further weight loss over the next hour and, in fact, a slight increase in weight to $13.4914 \mathrm{gm}$. The experiment was then terminated by removing the fabric from the balance.

Similar to the studies on paper, the gains and losses in weight for the cotton

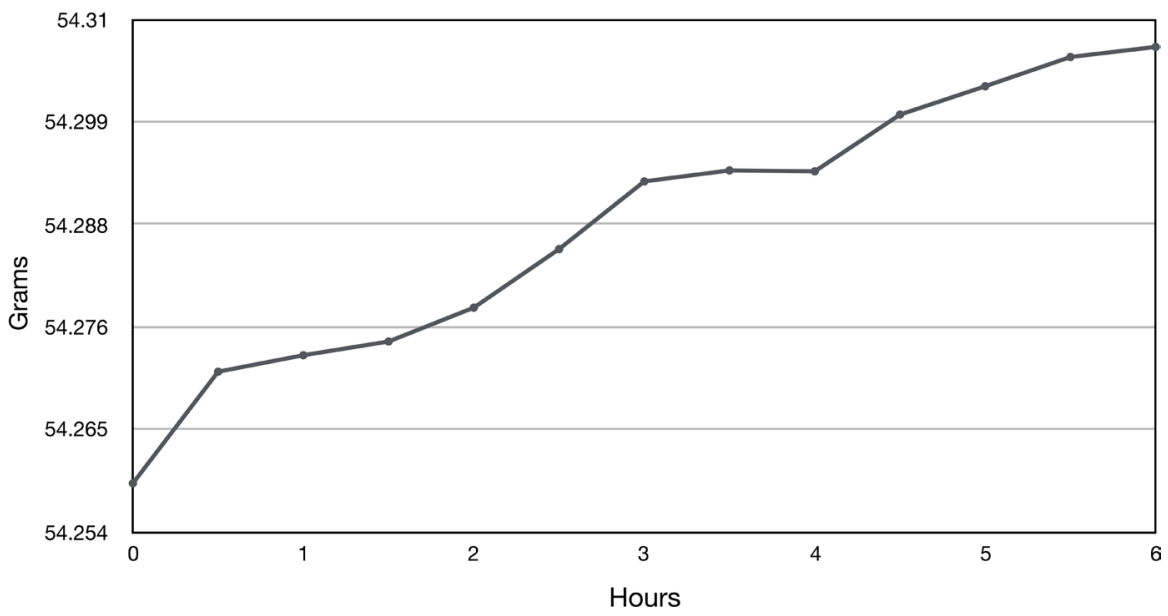

Figure 4. Gain in weight of cotton fabric placed near to containers of KELEA activated water. 


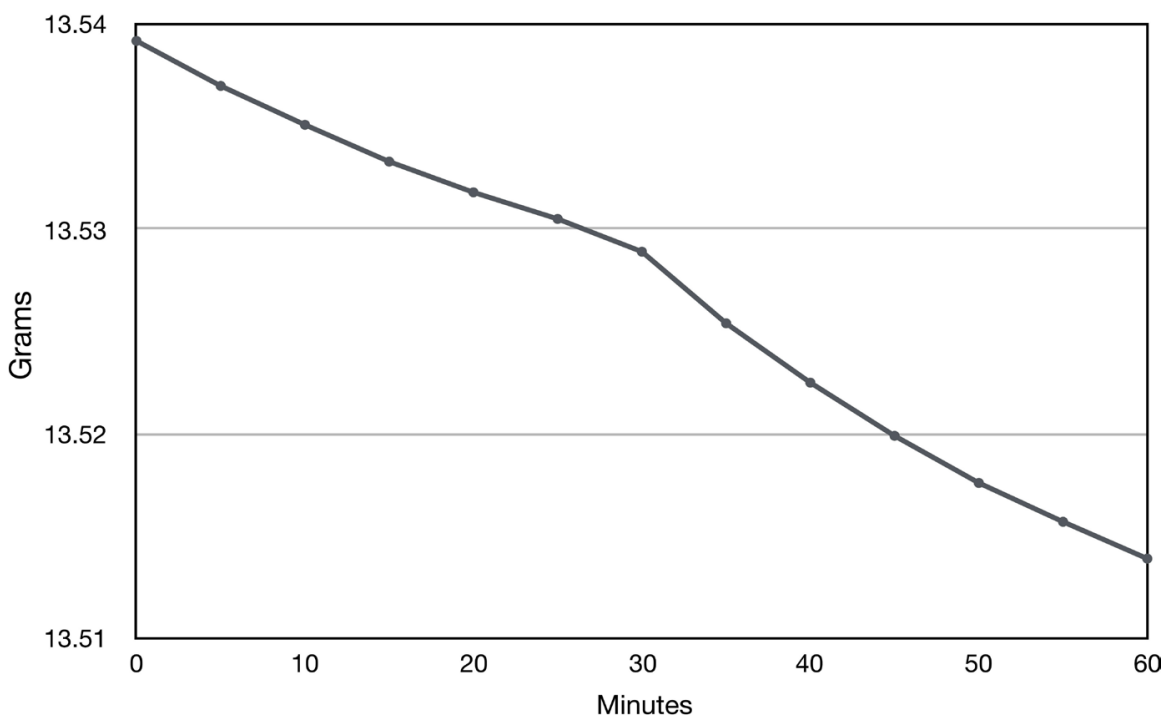

Figure 5. Loss of weight during the weighing of KELEA exposed cotton fabric.

fabrics have been in the range of several mg per gm. Unlike with paper, the weight changes have continued over much longer periods of time, even up to 36 hours. Another difference is that with some of the tested cotton fabrics, there have been several minutes of delay prior to the beginning of a meaningful decline in the measured weight. Moreover, the rates of weight loss of many of the tested cotton fabrics have been irregular and sometimes temporarily stalled. Not infrequently, the decline in weight is temporarily reversed with either slow or occasionally quite abrupt gains of weight of several mg or even more. Significant weight fluctuations are especially noticeable towards the lowest recorded weight and are usually followed by small but significant increases in weight. The rate of increase in the weight proceeds more rapidly after the cotton fabric is removed from the balance and placed near the KELEA activated water. The weight of the cotton fabric only marginally increases when it is removed from the balance and placed in another room for storage. Again, there was a general sense of increased sensitivity of printed cotton fabric.

Cotton fabric materials have allowed for some additional experiments. These included the following. 1) Leaving a relatively large piece of KELEA exposed cotton fabric inside the balance but away from the weighing pan in the balance did not affect the weighting of an unrelated item, the weight of which would remain unchanged. 2) Reweighing the cotton fabric, which had been placed in the active balance, but not on the weighing pan, showed a loss of its measured weight. 3) A cotton fabric, which showed a marked reduction in its weight in the electronic balance after it had been stored overnight in the weighing room, did not show any discernable weight loss when, after it was again stored overnight in the weighing room, it was subsequently weighed using a beam balance located in a different room. 4) Significant weight loss of a cotton fabric was achieved by placing the cotton fabric onto the speaker of a radio in which the volume of sound was set to zero. The overall weight loss of KELEA weight-enhanced cotton 
fabrics placed onto the radio speaker was generally greater than that achieved by the electronic balance. Figure 6 provides an example of the weight loss seen with a piece of cotton fabric placed onto the speaker of the radio. Similar results were seen with other active electronic devices including a television set, cell phone and 120 -volt electrical wiring.

An EMF meter was used to confirm that the electronic balance and the radio speaker would establish an electromagnetic field. High EMF levels were seen within the electronic balance, which varied from 155 to $578 \mu \mathrm{T}$ depending upon the placement of the meter within the balance. Only low levels $(<30 \mu \mathrm{T})$ were recorded away from the balance and elsewhere in the room, even when the balance was operating. The EMF level recorded on the speaker of the radio was higher than that recorded on the electronic balance and ranged from 1453 to $1667 \mu \mathrm{T}$. Other EMF emitting devices that could also reverse the KELEA acquired weight gain of cotton fabric included a television, an operating cell phone, and various electrical outlets. These EMF sources could also reduce the weight of KELEA exposed paper.

The results obtained with wood chips were similar, although less pronounced than those seen with the cotton fabric. Small pieces of cherry, hickory and pecan wood were weighed and then placed close to the containers of KELEA activated water in the weighing room. They were reweighed at approximately 1, 4, 9 and 21 hours later. Increases in weight occurred within the first hour with additional comparable increases occurring by 4 hours. The before and after readings of the three pieces of wood are recorded in Table 1. There were little subsequent changes in the weight measurements taken at 9 and 21 hours. The weight gains were not strikingly different for the three types of wood.

The three pieces of wood were collectedly placed onto the weighing pan of the electronic balance giving a combined initial recorded weight of $7.6462 \mathrm{gm}$. The weight of the wood chips was recorded at minute intervals for 40 minutes and

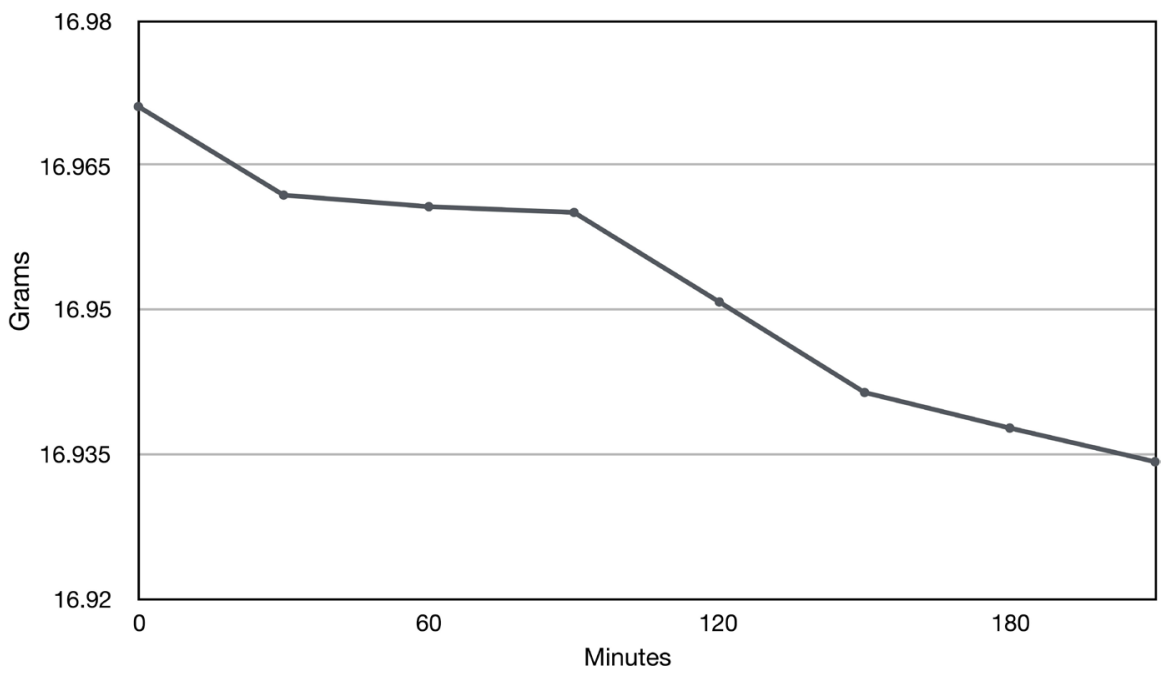

Figure 6. Loss of weight of KELEA exposed cotton fabric that was placed on the speaker of a radio. 
less frequently, thereafter, till 5 hours and 35 minutes had elapsed. The results over the first 40 minutes are shown in Figure 7. During this time there was a weight loss of $6.4 \mathrm{mg}$. The reductions in weight were interspersed with short periods of actual increases in weight. This fluctuation in weight was similar to that seen with the weighing of cotton fabrics. The overall weight loss of the wood is recorded in Table 2. At 5 hours and 35 minutes (335 minutes), the weight loss was $15.3 \mathrm{mg}$. The wood items were then taken out of the balance and placed near the containers of KELEA activated water. Seven minutes later the weight had increased by $3.6 \mathrm{mg}$ to $7.6345 \mathrm{gm}$. After an additional seventy-seven minutes, the weight had increased by an additional $4.3 \mathrm{mg}$ to $7.6388 \mathrm{gm}$. Thereafter, the weight remained essentially unchanged with a reading of $7.6689 \mathrm{gm}$ at 6 hours after the wood was taken out of the balance.

\section{Discussion}

Evidence was obtained in an earlier study for the weights of pieces of aluminum foil to fluctuate over time, with overall increases in the measured weights [1]. It was suggested that the added weight was due to the attraction of KELEA by areas of separated electrical charges, which were presumably present on the aluminum

Table 1. Gain in weight of wood chips placed near to containers of KELEA activated water.

\begin{tabular}{ccccccc}
\hline \multirow{2}{*}{$\begin{array}{c}\text { Duration of } \\
\text { Exposure } \\
\text { Hours }\end{array}$} & \multicolumn{2}{c}{ Cherry } & \multicolumn{2}{c}{ Hickory } & \multicolumn{2}{c}{ Pecan } \\
\cline { 2 - 6 } & Weight gm & $\begin{array}{c}\text { Gain in } \\
\text { Weight }\end{array}$ & Weight gm & $\begin{array}{c}\text { Gain in } \\
\text { Weight }\end{array}$ & Weight gm & $\begin{array}{c}\text { Gain in } \\
\text { Weight }\end{array}$ \\
\hline 0 & 2.5540 & - & 2.5064 & - & 2.5546 & - \\
1 & 2.5588 & $4.8 \mathrm{mg}$ & 2.5102 & $3.8 \mathrm{mg}$ & 2.5588 & $4.2 \mathrm{mg}$ \\
4 & 2.5667 & $12.7 \mathrm{mg}$ & 2.5164 & $10.0 \mathrm{mg}$ & 2.5647 & $10.1 \mathrm{mg}$ \\
9 & 2.5660 & $12.0 \mathrm{mg}$ & 2.5164 & $10.0 \mathrm{mg}$ & 2.5644 & $9.8 \mathrm{mg}$ \\
\hline
\end{tabular}

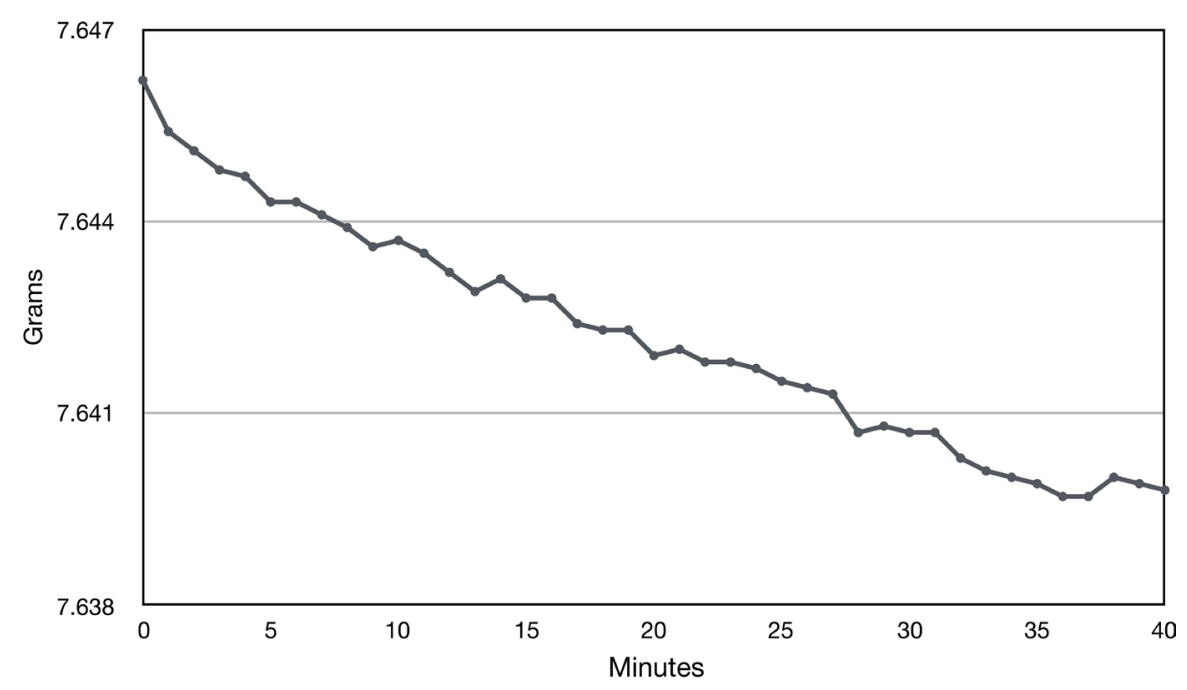

Figure 7. Loss of weight during the weighing of KELEA exposed wood. 
Table 2. Continuing weight loss of KELEA exposed wood at longer times of weighing.

\begin{tabular}{ccc}
\hline Minutes in the Balance & Weight (gm) & Weight Loss $(\mathrm{mg})$ \\
\hline- & 7.6462 & - \\
40 & 7.6398 & 6.4 \\
72 & 7.6369 & 9.3 \\
83 & 7.6358 & 10.4 \\
98 & 7.6351 & 11.1 \\
130 & 7.6339 & 12.3 \\
153 & 7.6331 & 13.1 \\
200 & 7.6325 & 13.7 \\
270 & 7.6310 & 15.2 \\
335 & 7.6309 & 15.3 \\
\hline
\end{tabular}

foil as a result of partial oxidation. The attraction of KELEA was probably also facilitated by the increased overall environmental level of KELEA in the room where the testing was performed. This is explainable because the room was and is still used to store containers of KELEA activated water.

Preliminary experiments showed variable increases in the weights of small pieces of humates and related water activating solid materials when they were simply stored adjacent to KELEA activated water. Inkjet-printed typing paper was viewed as possibly providing a more easily standardized KELEA detection system. Inkjet printing is based on the electrostatic binding of negatively charged ink onto paper or other surfaces [9]. The individual letters on the printed paper would presumably display the negative charge provided to the ink by the printer, in comparison to the non-printed regions of the paper. The separated electrical charges could, therefore, be expected to attract KELEA. Electrostatic painting onto metals would work similarly, except that the paint is positively charged and the surface to be painted has a temporarily induced negative electrical charge [10]. It was, therefore, also intended to test electrostatically painted metals with discrete fine droplets of positively charged paint for KELEA attracting capacity. In both study models, the presumptive attraction of KELEA was to be measured as weight gain. The somewhat surprising result from the first study model was the variability in weight measurements of regular paper, whether printed or not. This variability contrasted with the steady and reproducible weight measurements of most items. Along with certain other tested materials, it became clear that locating even a blank sheet of regular typing paper near KELEA activated water will lead to an increase in weight, as shown when the sheet of paper is subsequently reweighed. Moreover, continuing to weigh the slightly heavier sheet of paper in the electronic balance leads to the relatively rapid reversal of the prior weight gain. In other words, the added weight of the KELEA exposed paper was readily reversed during the subsequent continuing weighing of the paper in the electronic balance. As was predicted, KELEA induced weight gains 
followed by the electronic balance mediated reversal of the weight gain were also observed with other cellulose containing materials, including cotton fabrics and wood chips. The use of blank paper provided better standardization than using paper with printed text or using either cotton fabrics or wood. Overall, the findings suggest that, similar to humates, zeolites, and metal oxides [3], cellulose can acquire additional KELEA. Furthermore, the added KELEA can be readily removed or stripped from the energized cellulose by electromagnetic radiation. The various experiments reported in this article are consistent with this interpretation.

Before elaborating on this interpretation, it is helpful to summarize some of the recently proposed aspects of KELEA. These aspects extend beyond the presumed primary function of KELEA to prevent the fusion and elimination of electrostatically attracted opposite electrical charges [2] [3]. For example, it is likely that the combined level of KELEA on opposing electrical charges is inversely related to the closeness of the charges; with sufficient repulsive force remaining to prevent the annihilation of the finally juxtaposed opposite electrical charges. The proposed loss and gain of KELEA by approaching and separating electrical charges, respectively, on interacting chemical compounds may be the equivalent of what chemists refer to as the exchangeable chemical energy in linked chemical reactions. In other words, KELEA can be a source of chemical energy [11]. Consistent with this concept is the observation that KELEA emitting devices can increase the energy yield from the combustion of gasoline and diesel fuels [12] [13]. Also consistent with KELEA being a net source of chemical energy, is the abiotic production of lipids and aromatic chemicals in tubes that were previously used to culture stealth adapted viruses. The infected cells produce alternative cellular energy (ACE) pigments, which persist long after the cells have died [14]. KELEA attracting ACE pigments can lead to the synthesis of a wide range of organic compounds including hydrocarbons [14] [15]. Bacteria can also produce ACE pigments [16].

In addition to KELEA being an alternative (non-food calorie) source of cellular energy, it is likely to be directly involved in normal electrical functioning of the brain, sensory organs, and muscles, including the heart [17] [18] [19] [20]. It can add resilience to the unwarranted triggering of tissue-destructive and scaring inflammatory responses [21]. It can also lead to the regression of cancer through apoptosis [22] [23]. Indeed, many illnesses can be viewed as resulting from an insufficiency of cellular energy [24]. On the basis that KELEA provides life-enhancing benefits, the reductions in KELEA by the increasing manmade levels of electromagnetic radiation have undoubtedly had serious health consequences.

The environmental levels of manmade electromagnetic radiation have progressively increased in the $20^{\text {th }}$ and $21^{\text {st }}$ centuries [25] [26] [27] [28]. The enormous increase is estimated to be several million-fold. The major examples of increases in electromagnetic radiation have been the widespread uses of mi- 
crowaves and radio waves in local and distant communications; light pollution; the requirements for electrical power by numerous machines and other devices; and electrical energy transmissions, some of which occur within the ground (dirty electricity) [29]. By evoking the local formation of electrical charges, the increasing electromagnetic radiation has presumably reduced the availability of KELEA for various life forms, including humans, animals and plants. As noted above, given the many important biological functions attributed to KELEA, this will likely have many consequences. Indeed, a significant number of individuals attribute symptoms of their chronic illnesses to electropollution [26] [27] [28]. The findings in this paper imply that symptomatic relief for these individuals will likely be achievable through the consumption, inhalation, and both the direct and indirect exposure of the skin to KELEA activated water [30] [31] [32] [33] [34]. Clinical benefits should also come from various devices able to create a KELEA enhanced environment.

The current study raises interesting new topics for further study. Cellulose can now be added to the increasing array of natural products, which appear to have the capacity to variably attract KELEA. This is interesting since cellulose is one of the most abundant organic compounds on earth [35]. It is a polymer formed by the beta glycosidic covalent linkage of glucose molecules. The glucose molecules in cellulose retain separated electrical charges, which can engage in hydrogen bonding. Cellulose is the major component of plant cell walls, including the wood in trees. It also comprises much of the fibrous tissue in plants. Cotton is almost pure cellulose that provides a protective and dispersal mechanism for the seeds of the cotton plant [36] [37]. Paper and cotton fabrics are manufactured from the cellulose of trees and of cotton plants, respectively. In the formation of paper, the longer tree-derived cellulose polymers are disrupted into smaller units [38] [39] [40]. These units recombine to form mechanically interacting branched polymers. This would, presumably, lead to more exposure of free electrical charges and could explain why paper responds more quickly to the KELEA enriching and KELEA stripping environments than do wood and cotton fabrics. More so than with paper, wood and cotton fabrics can show brief periods of increasing weight while in the electronic balance. These weight increasing periods are interspersed with the more prolonged periods of declining weight and tend also to occur after the lowest weight is recorded. The findings are suggestive of competing KELEA addition and removal processes. The rather abrupt increases of several milligrams over 1 - 2 seconds in the weight of some cotton fabrics are also consistent with competing processes. It is reasonable to assume that different materials can variously attract and/or be stripped of added KELEA. Indeed, preliminary data support the idea that certain materials may actually be able to capture some of the KELEA, which is presumably normally associated with electromagnetic radiation. It will be interesting to compare the KELEA-delivering and removing capacities of various frequencies of electromagnetic radiation on different materials. 
It is generally assumed that photosynthesis is the primary source of energy for plants [41]. The apparent attraction of KELEA by cellulose can be viewed as a potential additional primary source of energy for plants. For example, it could be that increasing natural electromagnetic radiation from the sun in early spring could help in the release of some of the KELEA attracted to the cellulose of deciduous trees. The suggested release of KELEA from the tree cellulose into the tree's fluid compartments may contribute to the energy required for the rather spectacular rapid springtime formation of leaves by deciduous trees. Specifically, the released KELEA could possibly increase the permeability of the circulating fluids that supply nutrients and remove metabolic waste products from the tree. A natural energy augmenting function can similarly be envisioned for cellulose polymers in cotton. The widespread use of cotton in clothing and even as prayer cloths [42] is of further interest.

It is postulated that KELEA is being delivered to the earth in association with the charged particles comprising cosmic rays [43]. KELEA may, thereby, contribute to the ionization of atmospheric aerosols, leading to the formation of cloud condensation nuclei (CCN). Partial stripping of incoming KELEA by electromagnetic waves in the upper atmosphere could, therefore, potentially lead to a reduction in cloud formation. Lower level clouds are known to reflect some of the sun's thermal energy back into space. A reduction in cloud formation can, therefore, potentially lead to global warming. Some climatologists have argued that the intensities of cyclones, which are referred to in some locations as hurricanes, and of tornadoes, have increased over recent decades. There are still uncertainties as to the precise triggering of these events. The observed episodes of abrupt changes in the measured weights of certain objects could reflect similar phenomena occurring in Nature. It is not unreasonable, therefore, to suggest a linkage of rapidly changing atmospheric levels of KELEA with the local formation of cyclones and tornadoes. Wilhelm Reich advanced the idea that an energy, which he referred to as orgone and which is probably the same as KELEA, was able to alter the path of a hurricane [44].

The increases in weight of certain compounds from non-contact exposure to activated water and the progressive reductions in the added weight when the objects are being weighed in an electronic balance, require a rethinking of the concepts of weight and gravity. According to current theory as proposed by Einstein, weight is simply a passive reflection of the relative distortion of spacetime by the objects with that caused by the earth [45]. Objects are supposedly attracted to one another solely by the resulting curvature of the spacetime between the objects, and not as presumed by Isaac Newton to an unknown external or emitted force, which attracts distant objects. Nicolas Fatio in the $17^{\text {th }}$ century and Georges-Louis Le Sage in the $18^{\text {th }}$ century proposed an external pushing force coming from every direction [46]. Objects could potentially partially shield one another from the force acting in the area between the objects. The objects would, therefore, be pushed towards one another. This theory was abandoned 
mainly because it was wrongly assumed that the shielding would be a reflection of surface area rather than the mass of an object. The observed reversible reductions in the displayed weight of certain objects, together with periods of rapid and seemingly erratic fluctuations in the displayed weight, are clearly indicative of an additional component to weight beyond the distortion of spacetime. It may be time to revive some of the earlier considerations of Fatio and Le Sage [46].

As noted above, the results have major implications for the possibility of an overall decline in the health and vitality of all life forms. This decline may be corrected by the more widespread, routine use of KELEA activated water in humans, animals, and agriculture [30] [31] [32] [33] [34]. Efforts to achieve this goal are underway.

\section{Conclusion}

The results and discussion in this paper add to a better understanding of a natural force termed KELEA (kinetic energy limiting electrostatic attraction). Specifically, it supports an earlier notion that KELEA can add to the measured weight of certain materials. It also confirms that KELEA activated water can transfer energy to certain nearby objects. Increases in weight were shown for cellulose containing materials, including paper, cotton fabrics, and unprocessed wood, by simply being placed near KELEA activated water. The increases in weight were reversed by exposing the materials with the added weight to electromagnetic radiation, including that resulting from the use of an electronic balance. KELEA can be a source of chemical energy, as well as a means of increasing the permeability and nutrient delivery of the intra- and extracellular fluids in all life forms. Levels of manmade electromagnetic radiations are continuing to greatly increase. This has likely lowered the availability of the life promoting benefits of KELEA to humans, animals, and plants. This deficiency is potentially correctable by increasing the input of KELEA, including through the use of KELEA activated water. The article also postulates that, because of increased manmade electromagnetic radiation that a reduction has occurred in the cosmic rays delivery of KELEA to the lower atmosphere. This would likely reduce the amount of cloud formation contributing to global warming. The rate of decline in the weight of cotton fabrics while on an electronic balance was irregular and frequently interrupted by periods of partial and sometimes abrupt reversals. This suggested a dynamic and somewhat erratic KELEA addition and withdrawal process, which could also contribute to climate change. Another basic science implication of the results is a revival of the idea of a pushing gravity as previously proposed by Fatio and Le Sage. The article provides a simple approach to explore many of these interesting and important topics.

\section{Acknowledgements}

The research has been supported by MI Hope Inc., a non-profit public charity based in Los Angeles, CA, USA. 


\section{Conflicts of Interest}

The author declares no conflicts of interest regarding the publication of this paper.

\section{References}

[1] Martin, W.J. (2016) Journal of Modern Physics, 7, 461-472. https://doi.org/10.4236/jmp.2016.76048

[2] Martin, W.J. (2014) Stealth Adapted Viruses; Alternative Cellular Energy (ACE) \& KELEA Activated Water. Author House, Bloomingdale, IN, 321.

[3] Martin, W.J. (2016) Journal of Modern Physics, 7, 1995-2007. https://doi.org/10.4236/jmp.2016.715176

[4] Martin, W.J. (2016) International Journal of Complementary \& Alternative Medicine, 3, 00059.

[5] Martin, W.J. (2015) Open Journal of Biophysics, 5, 69-79. https://doi.org/10.4236/ojbiphy.2015.53006

[6] Martin, W.J. and Laurent, D. (2015) International Journal of Complementary \& Alternative Medicine, 2, 00045.

[7] Martin, W.J. (2015) Open Journal of Biophysics, 5, 115-121. https://doi.org/10.4236/ojbiphy.2015.54010

[8] Martin, W.J. (2015) International Journal of Complementary \& Alternative Medicine, $1,00034$.

[9] Hoath, S.D. (2016) Fundamentals of Inkjet Printing, The Science of Inkjet and Droplets. Wiley-VCH, Weinheim, Germany, 472. https://doi.org/10.1002/9783527684724

[10] Lutes, R.S. (1948) Electrostatic Painting Process. University of Cincinnati, Cincinnati, $\mathrm{OH}, 60$.

[11] Martin, W.J. (2017) MOJ Bioorganic \& Organic Chemistry, 1, 54-58.

[12] Martin, W.J. (2016) Journal of Transportation Technologies, 6, 148-154. https://doi.org/10.4236/jtts.2016.63014

[13] Martin, W.J. (2017) Open Journal of Air Pollution, 6, 103-116. https://doi.org/10.4236/ojap.2017.63009

[14] Martin, W.J. (2003) Experimental and Molecular Pathology, 74, 210-223. https://doi.org/10.1016/S0014-4800(03)00037-6

[15] Martin, W.J. (2014) The Alternative Cellular Energy (ACE) Pathway in the Repair of the Cytopathic Effect (CPE) Caused by Stealth Adapted Viruses, in Vitro and in Vivo Evidence Supporting a New Therapeutic Paradigm. In Stealth Adapted Viruses; Alternative Cellular Energy (ACE) \& KELEA Activated Water, Author House, Bloomington, IN, 31-70.

[16] Martin, W.J. (2005) Experimental Molecular Pathology, 78, 215-217. https://doi.org/10.1016/j.yexmp.2005.01.008

[17] Martin, W.J. (2016) Advances in Alzheimer's Disease, 6, 1-12. https://doi.org/10.4236/aad.2017.61001

[18] Martin, W.J. (2017) International Journal of Complementary \& Alternative Medicine, 4, Article ID: 00112.

[19] Martin, W.J. (2016) International Journal Complementary Alternative Medicine, 4, Article ID: 00118.

[20] Martin, W.J. (2017) World Journal of Neuroscience, 7, 257-266. 
https://doi.org/10.4236/wjns.2017.73021

[21] Martin, W.J. (2017) Journal of Cosmetics, Dermatological Sciences and Applications, 7, 82-98. https://doi.org/10.4236/jcdsa.2017.71009

[22] Martin, W.J. (2016) International Journal of Complementary \& Alternative Medicine, 3, Article ID: 00074. https://doi.org/10.15406/ijcam.2016.03.00074

[23] Martin, W.J. (2017) Journal of Cancer Therapy, 8, 1279-1290. https://doi.org/10.4236/jct.2017.813106

[24] Martin, W.J. (2016) International Journal of Complementary \& Alternative Medicine, 4, 00106.

[25] Global Electricity Transmission Report and Database 2016-2025. Global Transmission Reports, 3rd Edition, New Delhi.

[26] Bak, M. and Zmyślony, M. (2010) Medycyna Pracy, 61, 671-683.

[27] DeBaun, D.T. and DeBaun, R.P. (2017) Radiation Nation, Fallout of Modern Technology-Your Complete Guide to EMF Protection \& Safety, The Proven Health Risks of Electromagnetic Radiation (EMF) \& What to Do Protect Yourself \& Family. Icaro Publishing, St. Petersburg, FL.

[28] Becker, R.O. (1960) The Promise of Electromedicine: The Perils of Electropollution. JP Tarcher, New York, 326.

[29] Milham, S. (2012) Dirty Electricity, Electrification and the Diseases of Civilization. 2nd Edition, iUniverse Inc., Bloomington, 128.

[30] Martin, W.J. (2014) KELEA Activated Water-Enhancing the Alternative Cellular Energy (ACE) Pathway. In: Stealth Adapted Viruses, Alternative Cellular Energy (ACE) \& KELEA Activated Water, Author House, Bloomington, 115-144.

[31] Martin, W.J. (2015) Journal of Water Resource and Protection, 7, 1331-1344. https://doi.org/10.4236/jwarp.2015.716108

[32] Martin, W.J. (2014) Advances in Plants \& Agriculture Research, 2, Article ID: 00033. https://doi.org/10.15406/apar.2015.02.00033

[33] Martin, W.J. (2015) International Journal of Complementary \& Alternative Medicine, 1, Article ID: 00001. https://doi.org/10.15406/ijcam.2015.01.00001

[34] Martin, W.J. (2015) International Journal of Complementary \& Alternative Medicine, 2, Article ID: 00051. https://doi.org/10.15406/ijcam.2015.02.00051

[35] Brown, R.M. and Saxena, I.M. (2007) Cellulose Molecular and Structural Biology. Springer, The Netherlands, 379. https://doi.org/10.1007/978-1-4020-5380-1

[36] Hall, A.J. (1924) Cotton Cellulose, Its Chemistry and Technology. Ernest Benn Ltd., London, 228.

[37] Mahood, S.A. and Cable, D.E. (1922) Industrial \& Engineering Chemistry, 14, 727-730. https://doi.org/10.1021/ie50152a018

[38] Rolland, J.P. and Mourey, D.A. (2013) MRS Bulletin, 38, 299-333. https://doi.org/10.1557/mrs.2013.58

[39] Schmied, F.J., Teichert, C., Kappel, L., Hirn, U., Bauer, W. and Schennach, R. (2013) Scientific Reports, 3, Article No. 2432. https://doi.org/10.1038/srep02432

[40] Persson, B.N., Ganser, C., Schmied, F., Teichert, C., Schennach, R., Gilli, E. and Hirn, U. (2013) Journal of Physics: Condensed Matter, 25, Article ID: 045002. https://doi.org/10.1088/0953-8984/25/4/045002

[41] Pessarakli, M. (2016) Handbook of Photosynthesis. 3rd Edition, CRC Press, Boca Raton, 846. https://doi.org/10.1201/b19498 
[42] Eckhardt, J. (2010) Prayers That Bring Healing. Charisma Media, Lake Mary, 117.

[43] Martin, W.J. (2016) Atmospheric and Climate Sciences, 6, 174-179. https://doi.org/10.4236/acs.2016.62015

[44] Reich, W. (1942) The Discovery of the Orgone. Vol. 1, Orgone Institute Press, New York, 358.

[45] Einstein, A. (1920) Relativity: The Special and the General Theory. Henry Holt \& Co., New York, 168.

[46] Edwards, M.R. (2002) Pushing Gravity. New Perspective on Le Sage's Theory of Gravitation. C. Roy Keys Inc., Montreal, 316.

\section{Abbreviations}

KELEA-kinetic energy limiting electrostatic attraction, ACE-alternative cellular energy,

EMF-Electromagnetic Field,

mg-milligram,

$\mu \mathrm{T}$-microTeslars,

$\mathrm{Hz}$-Hertz,

oz-ounce,

lb-pound,

"-inches. 